\title{
Novel Use of Laser Scanning Confocal Microscopy to Image Dark Septate Endophytic Fungi in Cucurbita maxima
}

\section{Hulse JD $\mathbf{~}^{1,2}$}

\author{
${ }^{1}$ Miami University, 4D Upham Hall, Oxford OH, United States of America \\ ${ }^{2}$ Present Affiliation: Department of Biology and Department of Criminal Justice and Sociology, Robert C. Byrd Science \\ and Technology Center, Shepherd University, Shepherdstown, WV
}

Hulse JD 2020 - Novel use of laser scanning confocal microscopy to image Dark Septate Endophytic Fungi in Cucurbita maxima. Asian Journal of Mycology 3(1), 531-537, Doi 10.5943/ajom/3/1/20

\begin{abstract}
This manuscript provides a novel technical report on the first use of laser scanning confocal microscopy to image dark septate endophytic fungi. This research was conducted using the model organism, Cucurbita maxima, which is known for its diversely shaped and enormously sized fruits. Dark septate endophytic fungi are a paraphyletic group of fungi that convergently evolved to express phenotypes with highly melanized hyphae, septae, and are obligate endophytes of thousands of plant species. These fungi are known to be in association with various mycorrhizas ranging from arbuscular, orchidaceous, and ectomycorrhiza, although the ecological role of dark septate endophytic fungi within their host is still unclear. Dark septate endophytic fungal research has been documented with bright field light microscopy due to their melanized hyphae, but until now, no researchers have imaged dark septate endophytic fungi with laser scanning confocal microscopy. This manuscript provides the first laser scanning confocal micrographs of dark septate endophytic fungi and the first laser scanning confocal micrographs of dark septate endophyte fungi in Cucurbita maxima to date.
\end{abstract}

Key words - Agriculture - Biology - Ecology - Microbiology - Microscope - Mycology

\section{Introduction}

Dark septate endophytic fungi is a term for a paraphyletic group of endophytic fungi that inhabit the cortical cells of thousands of plant species (Jumpponen 2001, Mandyam \& Jumpponen 2005, Muthukumar et al. 2006, Thangavelu \& Tamilselvi 2010, Hulse 2018, Hulse \& Braselton 2019, Hulse 2020, Pandey et al. 2020). This diverse group have convergently evolved to express genes that correlate to highly melanized, septate hyphae, within an ecological niche as an obligate endophyte of plants (Hulse 2018). These taxa are found in association with various mycorrhiza, ranging from arbuscular, orchidaceous, and ectomycorrhiza, although the ecological role of dark septate endophytic fungi within their host is unclear (Jumpponen 2001, Mandyam \& Jumpponen 2005, Muthukumar et al. 2006, Pandey et al. 2020). In the past two decades, the phylogenetic relationships between dark septate endophytic fungi have been investigated with the use of molecular data, however, the phylogenies have not been resolved (Sarsaiya et al. 2020). Menkis et al. (2004) have dark septate endophytic fungi in association with both angiosperms and gymnosperms in Northern Europe, and dark septate endophytic fungi are of worldwide distribution. 
It is well known that dark septate endophytic fungi have an association with Arbuscular Mycorrhizal Fungi (AMF) and recent research suggest that dark septate endophytic fungi might have a competitive advantage over AMF by having higher colonization rates in the host plant compared to AMF (Fors et al. 2020). Although the extent of the relationship between dark septate endophytic fungi and AMF is still unclear, both provide independent protection against pathogens to the host plant, and synergistic effects between the two groups are documented (Muthukumar et al. 2006, Thangavelu \& Tamilselvi 2010). The molecular mechanisms behind this defense and amount of protection provided by each of these taxa are being investigated (Muthukumar et al. 2006).

Many areas of the world are contaminated by heavy metals leached from poor mining practices, as well as from conventional agricultural practices, heavy industries, and accidental spills. Certain members of the dark septate endophytic fungi aid host plants in their ability to bioremediate heavy metals such as mercury, and are reported to be resistant to cadmium, chrome, cobalt, lead, manganese, and zinc (Pietro-Souza et al. 2020). Interests in studying an organism that can help plants survive and remediate toxic and contaminated lands should be studied with greater importance in order to help these polluted communities.

Multigenerational interest into the effects of pollution combined with recently elevated interest into climate change has sparked novel research into the use of dark septate endophytic fungi to help plants adapt to the mounting environmental stresses they experience in a changing world (Chen et al. 2020). Stresses that a plant can succumb to include salt stress, temperature stress, moisture stress, and disease stress, which all can reduce yields of economically important crops, but also have more dire consequences on global species distribution (Chen et al. 2020). In a 2019-2020 study, dark septate endophytic fungi increase cold tolerances in the tropical plant Avicennia germinans, the Black mangrove, after being grown in soil containing dark septate endophytic fungal inoculum (Chen et al. 2020). Numerous other projects have indicated plant protective properties of dark septate endophytic fungi, which was used to alleviate host plant stresses to salt stress, moisture stress, and disease stresses.

Humans are facing extreme challenges in the medical field due to overreliance and overuse of traditional antibiotics, which has led to antibiotic resistance, and researchers are looking for novel substances that have antimicrobial properties (Praptiwi et al. 2020). It is well known that most current antibiotics come from fungi, which use these substances to protect their niche. Researchers are bioprospecting for organisms that display bioprotective properties which have different metabolisms from known antibiotic sources, and effectively have different biochemical pathways that retard the growth of bacteria (Praptiwi et al. 2020). Recent research into dark septate endophytic fungal metabolites have moderately active antibiotic properties, and could be a novel source for antibiotics in the field of medicine (Praptiwi et al. 2020). Further research into studying the protective properties of members in this diverse group of fungi should be initiated in order to combat antibiotic-resistant infections.

A member from the Cucurbita was selected as a model organism because it includes 13 species, each with worldwide economic importance (Hulse 2018, Hulse \& Braselton 2019, Hulse 2020). This genus includes Cucurbita maxima, or 'Winter Squash', which is known to produce the most morphologically diverse fruit of any species in this economically important clad (Hulse 2018, Hulse \& Braselton 2019, Hulse 2020). As the Latin binomial name suggests, C. maxima produce the largest fruit of any plant on Earth and also has the largest cotyledons in the genus. Cucurbita maxima evolved in South America and there is evidence of domestication over 4,000 years ago (Hulse 2018, Hulse \& Braselton 2019, Hulse 2020). Different varieties of C. maxima were taken to Europe in the $16^{\text {th }}$ century, and eventually were taken by European explorers to the Indian subcontent, and Southeast-Asia (Hulse 2018, Hulse \& Braselton 2019, Hulse 2020). Cucurbita maxima, as well as other members of the genus Cucurbita, have medicinal uses including antidiabetic, anti-oxidant, anticancer, and anti-inflammatory properties (Hulse 2018, Hulse \& Braselton 2019, Hulse 2020). Cucurbita maxima is also a food crop for a wide variety of world cultures due to its fiber content, carbohydrates, $\beta$-carotene, vitamins, alkaloids, minerals, fatty acids, flavonoid, 
and polysaccharide content (Hulse 2018, Hulse \& Braselton 2019, Hulse 2020).

Detection methods of dark septate endophytic fungi in host tissues have not been fully documented in the scientific literature and all of the images of these fungi have been produced using bright field light microscopy, dark field light microscopy, and electron microscopy, but laser scanning confocal micrographs (LSCM) are missing from the literature and is a crucial step in studying these elusive organisms (Hulse 2018). During the 1990s, a type of narrow field light microscope called a laser scanning confocal microscopy became a reliable method for visualizing mycorrhizal fungi (Melville et al. 1998). This technique uses glass optics to create individual sections of a specimen, then digitally reconstructs the individual sections into a three-dimensional image (Melville et al. 1998). The major advantage of using LSCM over bright field light microscopy is LSCM has great special resolution and much higher contrast than traditional light microscopy (Kubota et al. 2020).

The purpose of this study is to provide the first high-quality photomicrographs of dark septate endophytic fungi using laser scanning confocal microscopy and to provide the first technical report for using laser scanning confocal microscopy to image dark septate endophytic fungi in the economically important crop, Cucurbita maxima, to date. This technique is being used in a novel way and will progress mycological research into the biological diversity and host specificity of dark septate endophyte fungi.

Materials \& Methods See Hulse (2018) or as follows.

\section{Experimental Design}

Seedlings were planted on at Miami University's Ecology Research Center. Roots from $C$. maxima were sampled monthly, on July $2^{\text {nd }}$, August $2^{\text {nd }}$, September $2^{\text {nd }}$ and $3^{\text {rd }}, 2015$. During each sampling event, 10 plants of each variety were randomly destructively-sampled, and five roots from each plant were sub-sampled from the total roots collected. The individual roots were randomly cut into $1 \mathrm{~cm}$ segments and were selected for analysis.

\section{Seed Germination}

Seeds of Cucurbita maxima cv. Burgess Buttercup, Rouge Vif d'Etampes, Mariana de Chioggia, and Golden Hubbard were purchased from Seed Savers Exchange ${ }^{\bigcirc}$. Ten seeds of each cultivar were placed in filter paper lined Petri-plates, moistened with deionized water. This was replicated 10 times, for a total of 100 seeds of each cultivar. Seeds were incubated at $22^{\circ} \mathrm{C}$ under 24 hours of florescent lights. Seedlings were transferred from filer paper to 3" peat pots, filled with moistened Farfard ${ }^{\complement}$ 3B potting soil. Plants were grown on light carts or in light boxes under fluorescent lights at $22^{\circ} \mathrm{C}$ with a regime of 18 hours of light, and 6 hours of dark.

\section{Field Cultivation}

Research was conducted at Miami University's Ecology Research Center (ERC) on Somerville Road, north of Oxford, Butler County, Ohio. The field is approximately $1 / 2$ hectare in size and is adjacent to the ERC access road. The field was disked twice and tilled before planting. No chemical treatments were applied to the field pre- or post-planting.

Four-week-old seedlings of $C$. maxima cv. Burgess Buttercup, Rouge Vif d'Etampes, Mariana de Chioggia, and Golden Hubbard were transplanted in a non-randomized pattern that contained rows of 26 individuals, with $2.4 \mathrm{~m}$ spacing between the plants, and between the rows. Two rows of the same cultivar were planted adjacent to each other. Plants were irrigated by hand for the first 10 days post-planting.

\section{Root Sampling}

During each sampling event, 10 plants of each cultivar were randomly destructively sampled, and five roots from each plant were sub-sampled from the total roots collected. Sampling took place during three evenly spaced times during the growing season. The sampling took place on July 
$2^{\text {nd }}$, August $2^{\text {nd }}$, and September $2^{\text {nd }}$ and $3^{\text {rd }}, 2015$. Roots were stored in plastic bags at $4 \mathrm{C}$ until processing within 48 hours' post-harvest. Only one, $1 \mathrm{~cm}$ segment was used from each root, and the rest of the sample was frozen at $-80^{\circ} \mathrm{C}$ for future analysis.

\section{Microscopy}

Root segments were examined for distinct morphological features of dark septate endophytic fungi including melanized hyphae, microsclerotia, and various spores. These segments were first evaluated for the presence of dark septate endophytic fungi using bright field light microscopy and imaged with an Olympus AX-70 light microscope. Kumar et al. (2008) provided the methodologies that were adapted to this study using a Zeiss 710 laser scanning confocal microscope to fluorescently image dark septate endophytic fungi (Kumar et al. 2008).

\section{Results}

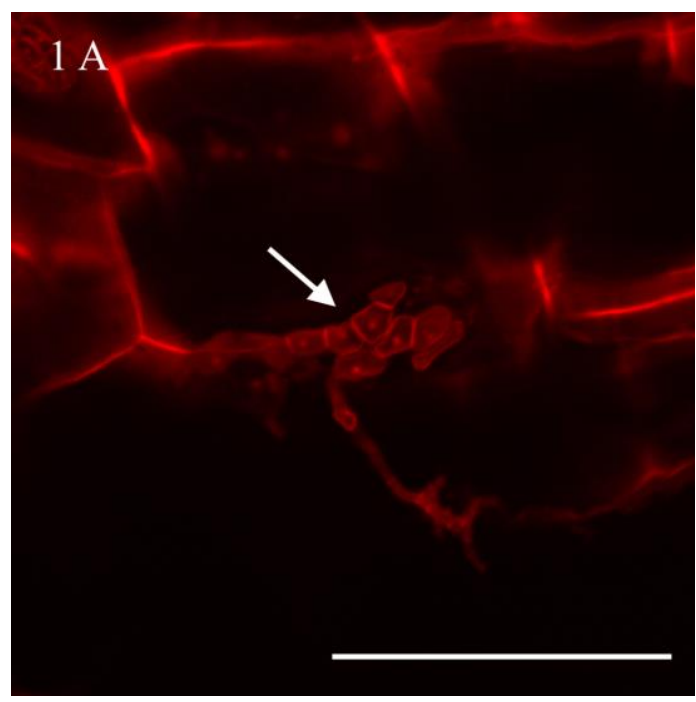

Fig. 1A - Laser scanning confocal micrograph of dark septate endophytic hyphae and microsclerotia imaged in Cucurbita maxima cortical root cells (shown with white arrow). Magnification bar is $20 \mu \mathrm{m}$.

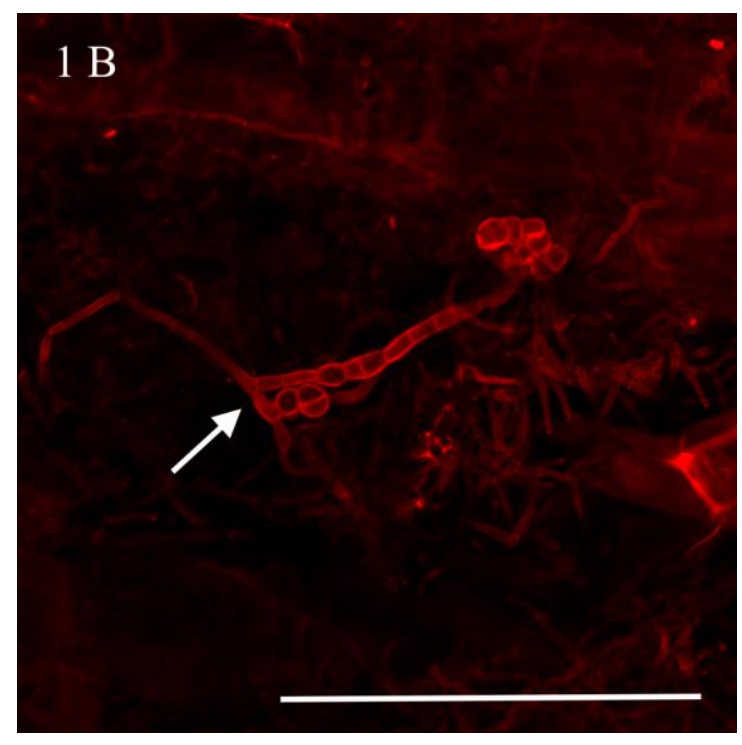

Fig. 1B - Laser scanning confocal micrograph of dark septate endophytic hyphae and microsclerotia imaged in Cucurbita maxima cortical root cells (shown with white arrow). Magnification bar is $20 \mu \mathrm{m}$ 


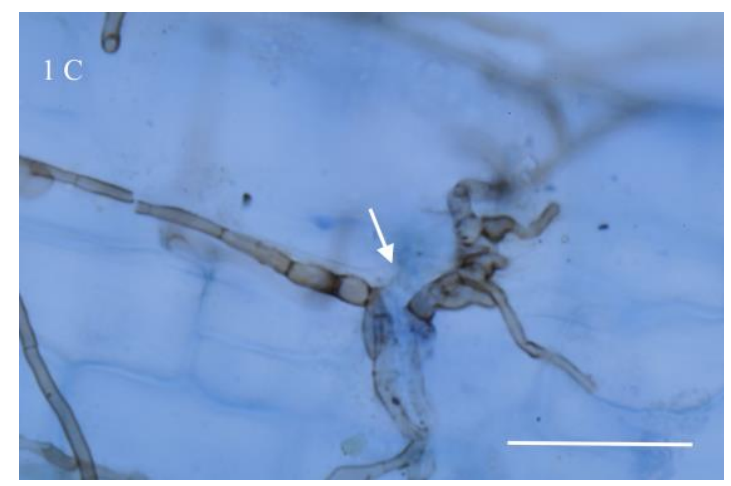

Fig. 1C - Bright field light micrograph of dark septate endophytic hyphae and microsclerotia imaged in Cucurbita maxima cortical root cells (shown with white arrow). Magnification bar is 10 $\mu \mathrm{m}$. Previously published in Hulse (2018), and serves as a positive control for dark septate endophytic fungi microscopy in C. maxima.

Slides were analyzed with protocols as stated in the methods section of this manuscript (See methods). Microsclerotia and hyphae were imaged with LSCM and compared to bright field light micrographs previously published by Hulse, which serve as a positive control in which to compare the photomicrographs produced in this study (Fig. 1C). The photomicrographs produced from the Kumar methods are high-resolution, and high contrast and are the first of their kind to date (Fig. 1A-B). Microsclerotia and hyphae from dark septate endophytic fungi were imaged with LSCF, showing high contrast, high resolution images (Fig. 1A-B).

\section{Discussion}

Dark septate endophytic fungi are a diverse paraphyletic group of fungi that inhabit the cortical tissues of thousands of plant species. Hulse (2018) provided the first documentation of dark septate endophytic fungi in $C$. maxima with the use of bright field light microscopy, and this current study furthers exploration into this novel relationship (Hulse 2018). In full, Cucurbita maxima is a model organism that has worldwide economic importance and is sought after for its diverse fruit (Hulse 2018). Microsclerotia and hyphae of dark septate endophytic fungi express highly melanized cell walls (Fig. 1C) and have been only been documented with traditional microscopic techniques in C. maxima (Hulse 2018).

Laser scanning confocal microscopy proves to be a very good alternative and a novel technique to image dark septate endophytic fungi in host plants, and more specifically, a new technique to image dark septate endophytic fungi in C. maxima (Fig. 1A \& B). Kumar et al. (2008) provided methodologies to image AMF with laser scanning confocal microscopy, which were adapted for this study to image dark septate endophytic fungi within root tissues of $C$. maxima (Kumar et al. 2008) The result of this study confirms the claim made by Kubota et al. (2020) that laser scanning confocal microscopy is a superior technique to traditional bright field light microscopy by providing greater resolution for dark septate endophytic fungi against the background of cortical cells (Kubota et al. 2020). This study provides high-resolution and high contrast images of dark septate endophytic fungi within $C$. maxima, and these methodologies can be applied to other research involving these fungi (Fig. 1A, B).

Future studies will be able to utilize this technique to image dark septate endophytic fungi in other host plants of ecological/economic importance and will provide as an alternative to bright field light microscopy. This manuscript will lead to forthcoming research into dark septate endophytic fungal cell-wall composition and florescent properties, which could lead to breakthroughs in understanding how dark septate endophytic fungi provide protective properties to the host plant. The micrographs of dark septate endophytic fungi provided in this manuscript are the first of their kind. This manuscript provides the first use of laser scanning confocal microscopy to image dark septate endophytic fungi. 


\section{Acknowledgements}

This research did not receive any specific grant from funding agencies in the public, commercial, or not-for-profit sectors. Internal funding was provided by Miami University for the Center for Advanced Microscopy and Imaging. Training and support were provided by Director Richard E. Edelmann and Microscopy Specialist Matthew L. Duley at the Center for Advanced Microscopy and Imaging at Miami University.

\section{Accessibility of data}

All rights are reserved to Jonathan D. Hulse and he grants permission to publish this material as an open source document.

\section{References}

Chen E, Blaze JA, Smith RS, Pen S, Byers JE. 2020 - Freeze-tolerance of poleward-spreading mangrove species weakened by soil properties of resident salt marsh competitor. Journal of Ecology 108, 1-13.

Fors RO, Júnior OJS, CarneiroM AC, Berbara RLL. 2020 - Selection of arbuscular mycorrhizal fungi for sugarcane in four soils with the presence of dark septate endophytes. Acta Scientiarum Agronomy 42, 1-12.

Hulse JD. 2018 - First Report of Dark Septate Endophytes imaged in Cucurbita maxima grown in the Eastern United States. Acta Scientific Agriculture 2, 61-64.

Hulse JD. 2020 - First report of the association of Genus Chaetomium with roots of Cucurbita maxima. Novel Research in Microbiology 4, 606-612.

Hulse JD, Braselton J. 2019 - Three-Dimensional rendering of an unidentified Plasmodiophorid Slime Mold in Cucurbita maxima roots using laser scanning confocal microscopy. Acta Scientific Agriculture 3, 205-210.

Jumpponen A. 2001 - Dark septate endophytes - are they mycorrhizal? Mycorrhiza 11, 207-211.

Kubota R, Nakamura K, Torigoe S, Hamachi I. 2020 - The Power of Confocal Laser Scanning Microscopy in Supramolecular Chemistry: In situ Real-time Imaging of Stimuli-Responsive Multicomponent Supramolecular Hydrogels. Chemistry Open 9, 67-79.

Kumar T, Majumdar A, Das P, Sarafis V, Ghose M. 2008 - Trypan blue as a fluorochrome for confocal laser scanning microscopy of arbuscular mycorrhizae in three mangroves. Biotechnic \& Histochemistry 83, 153-159.

Mandyam K, Jumpponen A. 2005 - Seeking the elusive function of the root-colonizing dark septate endophytic fungi. Studies in Mycology 53, 173-189.

Melville L, Dickson S, Farquhar ML, Smith SE, Peterson RL. 1998 - Visualization of mycorrhizal fungal structures in resin embedded tissues with xanthene dyes using laser scanning confocal microscopy. Canadian Journal of Botany 76, $174-178$.

Menkis A, Allmer J, Vasiliauskas R, Lygis V et al. 2004 - Ecology and molecular characterization of dark septate fungi from roots, living stems, coarse and fine woody debris. Mycological Research 108, 965-973.

Muthukumar T, Senthilkumar M, Rajangam M, Udaiyan K. 2006 - Arbuscular mycorrhizal morphology and dark septate fungal associations in medicinal and aromatic plants of Western Ghats, Southern India. Mycorrhiza 17, 11-24.

Pandey RR, Loushambam S, Srivastava AK. 2020 - Arbuscular mycorrhizal and dark septate endophyte fungal associations in two dominant ginger species of Northeast. National Academy of Science India 90, 885-894.

Pietro-Souza W, de Campos Pereira F, Mello IS, Stachack FFF et al. 2020 - Mercury resistance and bioremediation mediated by endophytic fungi. Chemosphere 240, 124874.

Praptiwi P, Fathoni A, Ilyas M. 2020 - Diversity of endophytic fungi from Vernonia amygdalina, their phenolic and flavonoid contents and bioactivities. Biodiversitas 21, 436-441. 
Sarsaiya S, Jain A, Jia Q, Fan X et al. 2020 - Molecular identification of endophytic fungi and their pathogenicity evaluation against Dendrobium nobile and Dendrobium officinale. International Journal of Molecular Sciences 21, 316.

Thangavelu M, Tamilselvi V. 2010 - Occurrence and morphology of endorhizal fungi in crop species. Tropical and Subtropical Agroecosystems 12, 593-604. 